\title{
Testing for Usability Is Not Enough: Why Clinician Acceptance of Health Information Systems Is also Crucial for Successful Implementation
}

\author{
Jasmine Croll \\ National ICT Australia, St Lucia, \\ Queensland, Australia \\ jasmine.croll@nicta.com.au
}

\begin{abstract}
Health Information Systems (HIS) are being implemented in all aspects of healthcare; from administration to clinical decision support systems. Usability testing is an important aspect of any HIS implementation with much done to deliver highly usable systems. However, evidence shows that having a highly usable system is not enough. Acceptance by the clinician users is critical to ensure that the HIS implemented is used fully and correctly. A longitudinal case study of the implementation of the Community Health Information Management Enterprise System (CHIME) in NSW is used to illustrate the importance of ensuring clinician acceptance of a HIS. A mixed methods approach was used that drew on both qualitative and quantitative research methods. The implementation of CHIME was followed from the early preimplementation stage to the post implementation stage. The usability of CHIME was tested using expert heuristic evaluation and a usability test with clinician users. Clinician acceptance of CHIME was determined using the Technology Acceptance Model (TAM). The clinician users were drawn from different community health service departments with distinctly different attitudes to information and communication technology (ICT) in healthcare. The results of this research identified that a successful implementation of a HIS is not a measure of its quality, capability and usability, but is influenced by the user's acceptance of the HIS.
\end{abstract}

Keywords: health information systems, acceptance, usability, information and communication technology.

\section{Introduction}

Health information systems are used in all aspects of healthcare from administration to prescriptions to clinical care [1]. ICT, via Health Information Systems (HIS), is used to manage this ever-growing health information generated by healthcare providers [2]. The different stakeholders in healthcare have a mixed reaction to the use of HIS, with some welcoming the many benefits in their drive towards increased safety and quality in healthcare. ICT in healthcare can bring increased accuracy, speed of access, portability, remote access, location awareness, access to more information 
resources, higher precision, and management of large data masses [3, 4, 5, 6, 7, 8]. However, these stakeholders, who include health managers, administrators, technicians, clinicians and nurses, can also be concerned about the detrimental aspects of health ICT. HIS can disrupt work practice, is expensive, could result in poorer quality of health care and make the users more inefficient. The confidentiality, security and privacy of health information can also be compromised. Poor usability and system failure of HIS can also result in many of these systems not being accepted or fully used $[9,10,11]$. Kushniruk et al [12] claimed that the ultimate acceptance or rejection of a HIS depended on the usability of that system.

Usability is defined as extent to which a product can be used by specified users to achieve specified goals with effectiveness, efficiency and satisfaction in a specified context of use [13]. Usability of HIS is a growing area with much research highlighting the importance of having highly usable systems. Poor usability can lead to failure of HIS. The increasing complexity and cross-platform operability of health information systems make it critical to ensure that the usability of these systems has been evaluated. The myriad changes in the healthcare environment require the development of information systems that are well designed and usable. Usability evaluation is a well researched area with many tried and tested methods including analytic, expert, observational, survey and experimental evaluations [14]. However, even well designed and usable systems can result in lack of acceptance by its users.

HIS clinician users can be unwilling to learn new routines and are uninvolved with the process of implementation. The negative impacts on the clinician-patient relationship that may result from use of a health information system while the patient is present can be of concern [5]. Clinician users are also unwilling to change their traditional long-standing practice patterns. Disruption to their established work roles results in resistance [11]. Some clinicians are computer illiterate and have low expertise in using the system. They may also have had to learn how to use Information and Communication Technology (ICT) without the benefit of formal study. Johnson [9] identified the lack of ICT training as a major barrier to the acceptance by clinicians and hence to the implementation of health information systems. Clinicians had fears concerning the effects of the system and had no intimate knowledge of it or responsibility for decisions relating to its implementation [6].

Johnson [9] stated that even a technically best system can be brought to its knees by users who have low psychological ownership in the system and who vigorously resist its implementation. Some clinicians simply do not bother to use it either fully or even partially [11]. They have a lack of insight about the benefits and are concerned about the sheer magnitude of the change caused by the health information system. Clinicians are also ambivalent about the changes that the health information system is designed to improve and are uninformed about its capabilities in that they actively discourage having the system or fail to support its use [9]. Clinicians are also burdened by the stress of anxiety about the new system, and ICT in general, resulting in high levels of stress and feelings of vulnerability in a profession which is already engulfed by enormous pressure and strain [7].

This paper presents a case study which illustrates why having a usable and welldesigned HIS is not enough without ascertaining clinician acceptance. 


\section{Method}

A mixed methods approach was used with both qualitative and quantitative research methods with an emphasis on the qualitative. It was a longitudinal (over the course of six months of a health information system implementation) case study. A community health information system, the Community Health Information Management Enterprise (CHIME) was implemented in two separate community health services in the Illawarra in New South Wales, namely, the Child Assessment Intervention Team (CA) in November, 2002, and the Aged Care Assessment Team (AC). CHIME is part of the Electronic Health Record Network or EHR *Net which provided web-enabled access to the personal clinical information held by the NSW public health system. CHIME is an amalgam of the Patient Administration System, the fundamental information infrastructure for all patient information systems, and the Point of Care Clinical Systems, which provides critical fundamental clinical data, in a community setting.

The two case studies comprised clinicians who were given training before the system was implemented. They were then interviewed over a series of stages: before the system was implemented and training given, after the training, after three months, and after six months. The usability of CHIME was also assessed by a variety of tests including heuristic evaluation and usability testing of the efficiency, effectiveness and satisfaction of the system. Clinician acceptance of CHIME was then examined using the Technology Acceptance Model to determine any relationship with the usability of CHIME.

There were 21 participants from Child Assessment (CA) and 10 participants from Aged Care (AC). These participants were clinicians in the two community health services. These two services (part of Community Health in the Illawarra Area Health Service) were selected by New South Wales Health to be the pilot sites for the implementation of a community health information system CHIME.

These services offered a range of specialists including nurse audiometrists, audiologists, psychologists, social workers, speech pathologists, occupational therapists, physiotherapists, nurse-clinicians (including enrolled and registered nurses) and clinical nurse consultants, occupational therapists, social workers, physiotherapists and dementia specialists.

The following table shows the stages, timing and type of data collection.

Table 1. The Stages, Timing and Type of Data Collection

\begin{tabular}{lll}
\hline Stage & Timing & Data Collection \\
\hline 1 & 2 weeks before implementation & Interviews, User \\
& & Profile Quetionnaire \\
& Interviews, TAM \\
2 & After 4 days of training & $\begin{array}{l}\text { Questionnaire } \\
\text { TAM Questionnaire, }\end{array}$ \\
3 & After 3 months & Interviews, Heuristic \\
& & Evaluation \\
4 & After 6 months & Usability Test \\
& & \\
\hline
\end{tabular}


The multi-methods approach in usability and acceptance evaluation resulted in the use of a variety of instruments to collect the data in this research. The instruments used included semi-structured interviews, questionnaires, checklists and testing. All the instruments were planned and used at specified times. For Stage 1, there was a User Profile questionnaire, and individual semi-structured interviews. Stage 2 and Stage 3 utilized the Technology Acceptance Model questionnaire and semi-structured interviews, and the heuristic evaluation checklist and for Stage 4, a usability test was done. For the purposes of this paper, only the TAM questionnaire and usability evaluations will be considered.

\subsection{Usability Evaluation of CHIME}

The usability of CHIME was evaluated using two standard methods; heuristic evaluation and a usability test. Heuristic evaluation is a usability engineering method used for finding the usability problems in a user interface design [15]. A small set of experts examine the CHIME interface and judged its compliance with recognised usability principles (the heuristics). These heuristics are:

1. Visibility of System Status

2. Match Between System and the Real World

3. User Control and Freedom

4. Consistency and Standards

5. Help Users Recognize, Diagnose, and Recover From Errors

6. Error Prevention

7. Recognition Rather Than Recall

8. Flexibility and Minimalist Design

9. Aesthetic and Minimalist Design

10. Help and Documentation

11. Skills

12. Pleasurable and Respectful Interaction with the User

13. Privacy [16]

A usability test was also used to evaluate CHIME with specific tests to measure the interactions between the system and the users for efficiency, effectiveness and satisfaction. Satisfaction was measured using the QUIS. Five significant tasks in a performance test were undertaken by the clinicians. These were: Application Basics; Client Notes; Diary; Service Request Folder and Episode Service Request. Software called Camtasia was used to record the clinicians' efficiency and effectiveness of CHIME by measuring the time taken to complete tasks, counting the number of mouse clicks, the observation of errors, and observing how the clinicians used CHIME. Satisfaction of CHIME was tested using the Questionnaire for User Interaction Satisfaction (QUIS), a tool developed by a multi-disciplinary team of researchers at the University of Maryland. This tool was designed to assess users' subjective satisfaction with specific aspects of the human-computer interface including: Overall User Reaction; Screen; Terminology and System Information; Learning; System Capabilities; Technical Manuals and Online Help; Online Tutorials; 
Multimedia; Teleconferencing and Software Installations. The interviews conducted at the different stages of the CHIME implementation also gave rich information about the usability of CHIME.

\subsection{Acceptance Evaluation of CHIME}

Acceptance of CHIME was measured using the Technology Acceptance Model [17]. The Technology Acceptance Model (TAM) [17] is based on Ajzen and Fishbein's Theory of Reasoned Action [18,19] which was developed to explain human behaviour that is under voluntary control.

Davis [17] adapted the Technology Acceptance Model and designed it specifically to model user acceptance of information systems. The model suggests that when users are presented with new technology, a number of factors influence their decision about how and when they will use it.

The two main factors are the perceived usefulness (PU) and the perceived ease of use (PEOU). Davis [17] defined PU as "the degree to which a person believes that using a particular system would enhance his or her job performance" (p. 320). PEOU is defined as "the degree to which a person believes that using a particular system would be free from effort" (p.320). In other words, PU and PEOU would be able to predict computer systems users' acceptance behaviours [20]. The Technology Acceptance Model asserts that the influence of external variables upon user behaviour is mediated through user beliefs and attitudes (see Figure 1).

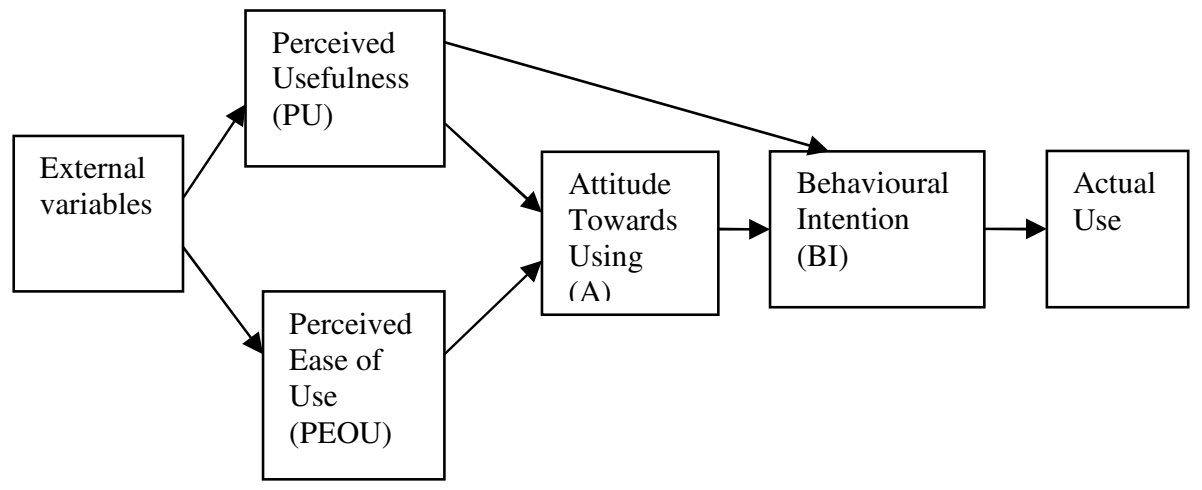

Fig. 1. Technology Acceptance Model (TAM)

\section{Results}

\subsection{Usability Evaluation Results}

The results of the heuristic evaluation are presented in Table 2. These show the heuristics, the percentage of problems identified by the three experts and a description of the usability problems of CHIME. None of the experts found more than $35 \%$ of usability problems with CHIME. Nielsen (2003) stated that this is an acceptable percentage which would evaluate a system as usable. The usability problems identified 
Table 2. Results of Expert Usability Testing

\begin{tabular}{|c|c|c|c|c|}
\hline Heuristics & Expert1 & Expert2 & Expert3 & Description of usability problems \\
\hline $\begin{array}{l}\text { Visibility of System } \\
\text { Status }\end{array}$ & $28 \%$ & $21 \%$ & $21 \%$ & $\begin{array}{l}\text { No header or title that described the screen. } \\
\text { The error messages did not allow the user to } \\
\text { see the field in error. The response time was } \\
\text { inappropriate to the task (it took too long) in } \\
\text { the organisation unit diary. The menu naming } \\
\text { terminology was not consistent with the } \\
\text { user's task domain as it was not logical and } \\
\text { the term service provider should have read } \\
\text { health worker instead }\end{array}$ \\
\hline $\begin{array}{l}\text { Match between } \\
\text { System and the Real } \\
\text { World }\end{array}$ & $4 \%$ & $17 \%$ & $8 \%$ & $\begin{array}{l}\text { As seen in the diary, the language was not in } \\
\text { line with the real world. The numbered codes } \\
\text { (ICDT10) should have be omitted, if possible }\end{array}$ \\
\hline $\begin{array}{l}\text { User Control and } \\
\text { Freedom }\end{array}$ & $25 \%$ & $28 \%$ & $22 \%$ & $\begin{array}{l}\text { Users could not rearrange window on the } \\
\text { screen. Users could not switch between } \\
\text { windows when using overlapping windows. } \\
\text { Users could not type ahead. Once saved, } \\
\text { users could not reverse their actions }\end{array}$ \\
\hline $\begin{array}{l}\text { Consistency and } \\
\text { Standards }\end{array}$ & $30 \%$ & $25 \%$ & $32 \%$ & $\begin{array}{l}\text { The method for moving the cursor to the next } \\
\text { or previous field was not consistent. Pages in } \\
\text { multi-page data entry screens did not have the } \\
\text { same title. In multi-page data entry screens, } \\
\text { pages did not have a sequential page number. }\end{array}$ \\
\hline $\begin{array}{l}\text { Help Users } \\
\text { Recognize, Diagnose, } \\
\text { and Recover From } \\
\text { Errors }\end{array}$ & $4 \%$ & $4 \%$ & $4 \%$ & $\begin{array}{l}\text { The prompts needed to be brief and use } \\
\text { simpler language. }\end{array}$ \\
\hline Error Prevention & $34 \%$ & $30 \%$ & $30 \%$ & $\begin{array}{l}\text { Users had to enter one group of data at a time. } \\
\text { When the system displayed multiple } \\
\text { windows, navigation between windows was } \\
\text { tedious. In the service request wizard for } \\
\text { issues and diagnosis comment field, the } \\
\text { number of characters available was not } \\
\text { indicated. }\end{array}$ \\
\hline $\begin{array}{l}\text { Recognition Rather } \\
\text { Than Recall }\end{array}$ & $0 \%$ & $0 \%$ & $0 \%$ & None \\
\hline $\begin{array}{l}\text { Flexibility and } \\
\text { Minimalist Design }\end{array}$ & N.A. & N.A. & N.A. & Not Applicable (N.A.) \\
\hline $\begin{array}{l}\text { Aesthetic and } \\
\text { Minimalist Design }\end{array}$ & $6 \%$ & $10 \%$ & $13 \%$ & $\begin{array}{l}\text { All information not just the essential was } \\
\text { displayed on the screen. The data entry } \\
\text { screens did not have a short, simple, } \\
\text { clear, distinctive title. }\end{array}$ \\
\hline $\begin{array}{l}\text { Help and } \\
\text { Documentation }\end{array}$ & $0 \%$ & $0 \%$ & $0 \%$ & None \\
\hline Skills & N.A. & N.A. & N.A. & Not Applicable (N.A.) \\
\hline $\begin{array}{l}\text { Pleasurable and } \\
\text { Respectful } \\
\text { Interaction with } \\
\text { the User }\end{array}$ & $4 \%$ & $8 \%$ & $4 \%$ & $\begin{array}{l}\text { The amount of window housekeeping } \\
\text { when linking activities in the diary to } \\
\text { phase in tree-view needed to be kept to a } \\
\text { minimum. }\end{array}$ \\
\hline Privacy & $0 \%$ & $0 \%$ & $0 \%$ & None \\
\hline
\end{tabular}


by the expert evaluators were, in general, minor. This uncovering of minor problems is one of the results of doing heuristic evaluation [21]. Based on the results, CHIME addressed many of the concerns that would have affected its usability. It kept users informed via appropriate feedback and used language that was pertinent although some of the medical terminology needed changing. Users were able to select and sequence tasks freely. However, CHIME did not cater to a wide range of users as a certain level of skill and competence was expected. This was expected as this system had been specifically designed to bring community health information into the electronic health record. The help and documentation was user-centred with easy to search information. It was also aesthetically pleasing.

The results according to the experts were that, overall, CHIME was a usable system. Any usability problems identified were minor compared to what the system could achieve in terms of managing the community health data. Such a usable system should therefore have no problems being accepted by its users.

The second usability evaluation was the usability test where the three determinants of usability; efficiency, effectiveness and satisfaction, were measured separately.

The efficiency of CHIME was measured by the time it took the clinicians to perform the five tasks. The results indicated that the clinicians performed slower at some of the tasks than the others. There were a variety of reasons for this including, the complexity of the tasks, the production of and the care with which some clinicians performed the tasks. Compared against the benchmark times, the clinicians appeared not to have performed as efficiently. A compelling explanation for the poorer performance by the clinicians is that the benchmark times by the expert user was because he was working with information from the training sessions as he was not a clinician. He had no qualms about making errors or keying in incorrect details. The clinicians, on the other hand, were working with real data in real time. They were exercising the same level of professional care with the tasks as they would in their normal work practice. Their concern was not to achieve the fastest times but to ensure that they performed the tasks as accurately as possible.

It must be noted that the expert user used client information from the training sessions as he was not an actual clinician. The clinicians, however, were working with real data in real time situations. The overall results could imply that as a system, CHIME is not as efficient as it is effective. However, the type of client information used in the tests must be taken into account.

The ISO 9241-11 Standard for Usability [13] stated that effectiveness, as a determinant of usability, is measured in terms of the accuracy and completeness with which users achieve specified goals. CHIME's effectiveness was tested in terms of accuracy, that is, whether errors were produced, and completeness, that is, finishing all the steps of the tasks.

In terms of accuracy, the number of errors made both simple recoverable and critical irrecoverable was small; not higher than four per task. The clinicians had to perform a large number of steps in completing the tasks, some of which were complex. Although the critical errors were not able to be removed from the permanent record, they consisted of typographical errors not errors of diagnosis or outcomes. The simple errors were mostly that of mistyped passwords and failure to click or follow navigational direction on the system. These errors did not stop the clinicians from completing the tasks. 
The results of the tests for the effectiveness of CHIME in terms of completeness indicate how more than $70 \%$ of the clinicians managed to finish all of the steps of the tasks. The unsuccessful clinicians did not complete all the steps of the tasks because they made mistakes, stopped to check details or stopped doing the task. The tasks ranged from simple to complex and involved a series of steps. A high majority of the clinicians were able to navigate successfully through the steps of the tasks. A low rate of error production and a high rate of completion indicate that, CHIME is an effective and, therefore, usable system.

The satisfaction of CHIME was measured using QUIS. The results indicated that the clinicians found the system to be neither satisfying nor unsatisfying. Examination of the different sections indicated that the clinicians did find certain aspects of the system to be positive, for example, the quietness of the system, the ease of operation and their own abilities to respond to commands. However, the majority of the responses were negative, in particular the undoing of operations and the number of steps for each task. Many of the responses were at the neutral midpoint value of 5 indicating that the clinicians did not have a strong opinion on whether or not CHIME, as a system, was satisfying to use.

CHIME, in terms of the third determinant of usability, neither satisfied nor unsatisfied its users.

Table 3. Stage 2 Perceived Usefulness

\begin{tabular}{|c|c|c|}
\hline Perceived Usefulness & AC Clinicians & CA Clinicians \\
\hline $\begin{array}{l}\text { Using Chime would improve my } \\
\text { job performance }\end{array}$ & $\begin{array}{l}30 \% \text { would not at all } \\
20 \% \text { would slightly not } \\
\text { at all } \\
40 \% \text { neutral } \\
10 \% \text { would slightly }\end{array}$ & $\begin{array}{l}75 \% \text { would not at } \\
\text { all } \\
19 \% \text { neutral } \\
6 \% \text { would } \\
\text { slightly }\end{array}$ \\
\hline $\begin{array}{l}\text { Using Chime would make it } \\
\text { easier to do my job }\end{array}$ & $\begin{array}{l}90 \% \text { would not } \\
10 \% \text { would slightly }\end{array}$ & $\begin{array}{l}63 \% \text { would not } \\
38 \% \text { neutral }\end{array}$ \\
\hline $\begin{array}{l}\text { Using Chime would enhance my } \\
\text { effectiveness on the job }\end{array}$ & $\begin{array}{l}70 \% \text { would not } \\
30 \% \text { neutral }\end{array}$ & $\begin{array}{l}69 \% \text { would not } \\
25 \% \text { neutral } \\
6 \% \quad \text { would } \\
\text { slightly }\end{array}$ \\
\hline $\begin{array}{l}\text { Using CHIME in my job would } \\
\text { increase my productivity }\end{array}$ & $\begin{array}{l}70 \% \text { would not } \\
20 \% \text { neutral } \\
10 \% \text { would slightly }\end{array}$ & $\begin{array}{l}75 \% \text { would not } \\
25 \% \text { neutral }\end{array}$ \\
\hline $\begin{array}{l}\text { Using CHIME in my job would } \\
\text { enable me to accomplish tasks } \\
\text { more quickly }\end{array}$ & $\begin{array}{l}60 \% \text { would not } \\
30 \% \text { neutral } \\
10 \% \text { would slightly }\end{array}$ & $\begin{array}{l}69 \% \text { would not } \\
19 \% \text { neutral } \\
13 \% \text { would } \\
\text { slightly }\end{array}$ \\
\hline $\begin{array}{l}\text { I would find CHIME useful in my } \\
\text { job }\end{array}$ & $\begin{array}{l}70 \% \text { would not } \\
20 \% \text { neutral } \\
10 \% \text { would definitely }\end{array}$ & $\begin{array}{l}56 \% \text { would not } \\
25 \% \text { neutral } \\
19 \% \text { would } \\
\text { slightly }\end{array}$ \\
\hline
\end{tabular}




\subsection{Acceptance Evaluation Results}

The clinician acceptance of CHIME was evaluated in Stage 2 after the 4 days of training, and Stage 3 after three months of use. The results of the Perceived Usefulness and Perceived East of Use in the TAM are seen in the tables below.

Table 4. Stage 2 Perceived Ease of Use

\begin{tabular}{llll}
\hline \multicolumn{1}{c}{ Perceived Ease of Use } & $\begin{array}{c}\text { AC } \\
\text { Clinicians }\end{array}$ & \multicolumn{1}{c}{ CA Clinicians } \\
\cline { 1 - 2 } $\begin{array}{ll}\text { Learning to operate CHIME would be } \\
\text { easy for me }\end{array}$ & $\begin{array}{l}10 \% \text { not at all } \\
20 \% \text { neutral }\end{array}$ & $\begin{array}{l}25 \% \text { not at all } \\
44 \% \text { neutral }\end{array}$ \\
& $\begin{array}{l}40 \% \text { slightly } \\
30 \% \text { definitely }\end{array}$ & $\begin{array}{l}13 \% \text { slightly } \\
19 \% \text { definitely }\end{array}$ \\
My interaction with CHIME would be clear & $20 \%$ not at all & $38 \%$ not at all \\
and understandable & $50 \%$ neutral & $31 \%$ neutral \\
& $30 \%$ slightly & $18 \%$ slightly \\
& & $13 \%$ definitely \\
It would be easy for me to become skilful at & $10 \%$ would not & $13 \%$ would not \\
using CHIME & $20 \%$ neutral & $25 \%$ neutral \\
& $40 \%$ slightly & $44 \%$ slightly \\
& $30 \%$ definitely & $19 \%$ definitely \\
I would find it easy to get CHIME to do & $30 \%$ did not & $69 \%$ did not \\
what I want & $40 \%$ neutral & $19 \%$ neutral \\
& $30 \%$ slightly & $6 \%$ slightly \\
& & $6 \%$ definitely \\
I would find CHIME to be flexible to & $100 \%$ did not & $81 \%$ did not \\
interact with & & $13 \%$ neutral \\
& & $6 \%$ slightly \\
I would find CHIME easy to use & $30 \%$ did not & $50 \%$ did not \\
& $30 \%$ neutral & $19 \%$ neutral \\
& $30 \%$ slightly & $19 \%$ slightly \\
& $10 \%$ definitely & $13 \%$ definitely \\
\hline \hline
\end{tabular}

The overall finding at this stage is that clinicians at both health services did not perceive CHIME to be useful. From these results it is clear that the clinicians from both services find CHIME to be the problem rather than their own skills at learning to use it.

After three months of usage, the results of the TAM is represented in Tables 5 and 6

Again, as in Stage 2, the overall finding at this stage is that clinicians at both health services did not accept CHIME after using the system for three months. 
Table 5. Stage 3 Perceived Usefulness

\begin{tabular}{|c|c|c|}
\hline Perceived Usefulness & AC Clinicians & CA Clinicians \\
\hline $\begin{array}{l}\text { Using CHIME has improved my job } \\
\text { performance }\end{array}$ & $\begin{array}{l}90 \% \text { had not at all } \\
10 \% \text { neutral }\end{array}$ & $\begin{array}{l}95 \% \text { had not at all } \\
5 \% \text { neutral }\end{array}$ \\
\hline $\begin{array}{l}\text { Using CHIME has made it easier to } \\
\text { do my job }\end{array}$ & $\begin{array}{l}90 \% \text { had not } \\
10 \% \text { would slightly }\end{array}$ & $\begin{array}{l}95 \% \text { had not at all } \\
5 \% \text { slightly }\end{array}$ \\
\hline $\begin{array}{l}\text { Using CHIME has enhanced my } \\
\text { effectiveness on the job }\end{array}$ & $\begin{array}{l}90 \% \text { had not at all } \\
10 \% \text { neutral }\end{array}$ & $\begin{array}{l}95 \% \text { had not at all } \\
5 \% \text { slightly }\end{array}$ \\
\hline $\begin{array}{l}\text { Using CHIME in my job has } \\
\text { increased my productivity }\end{array}$ & $\begin{array}{l}90 \% \text { had not } \\
10 \% \text { would slightly }\end{array}$ & $\begin{array}{l}95 \% \text { had not at all } \\
5 \% \text { slightly }\end{array}$ \\
\hline $\begin{array}{l}\text { Using CHIME in my job has enabled } \\
\text { me to accomplish tasks more quickly }\end{array}$ & $\begin{array}{l}60 \% \text { had not } \\
30 \% \text { neutral } \\
10 \% \text { would slightly }\end{array}$ & $\begin{array}{l}95 \% \text { had not at all } \\
5 \% \text { slightly }\end{array}$ \\
\hline $\begin{array}{l}\text { I have found CHIME useful in my } \\
\text { job }\end{array}$ & $\begin{array}{l}50 \% \text { had not } \\
20 \% \text { neutral } \\
30 \% \text { had slightly }\end{array}$ & $\begin{array}{l}71 \% \text { had not } \\
14 \% \text { neutral } \\
10 \% \text { had slightly } \\
5 \% \text { had definitely }\end{array}$ \\
\hline
\end{tabular}

Table 6. Stage 3 Perceived Ease of Use

\begin{tabular}{lll}
\hline Perceived Ease of Use & AC Clinicians & CA Clinicians \\
\cline { 3 - 3 } Learning to operate CHIME was easy for & $30 \%$ not at all & $24 \%$ not at all \\
me & $10 \%$ neutral & $38 \%$ neutral \\
& $50 \%$ slightly & $29 \%$ slightly \\
& $10 \%$ definitely & $10 \%$ definitely \\
My interaction with CHIME was clear & $30 \%$ not at all & $39 \%$ not at all \\
and understandable & $20 \%$ neutral & $17 \%$ neutral \\
& $40 \%$ slightly & $44 \%$ slightly \\
& $10 \%$ definitely & \\
I have become skilful at using CHIME & $40 \%$ had not & $5 \%$ had not \\
& $20 \%$ neutral & $33 \%$ neutral \\
& $20 \%$ slightly & $38 \%$ slightly \\
& $20 \%$ definitely & $24 \%$ definitely \\
I have found it easy to get CHIME to do & $80 \%$ did not & $76 \%$ did not \\
what I want & $20 \%$ neutral & $24 \%$ neutral \\
I have found CHIME to be flexible to & $100 \%$ did not & $100 \%$ did not \\
interact with & & \\
I have found CHIME easy to use & $50 \%$ did not & $40 \%$ did not \\
& $40 \%$ neutral & $40 \%$ neutral \\
\end{tabular}




\section{Conclusion}

The main result in this research was that having the most usable system is not the crux; it is having a system that is accepted by its users that is important. The findings from this research confirmed that usability of a system was indeed focused on the users. The CHIME system was evaluated by the expert heuristic evaluation and found to be a usable system; however, the users did not accept it and therefore it became unusable. The key finding in the literature review for this research was Kushniruk et al. [12] who asserted that the ultimate acceptance or rejection of a health information system depended to a large extent on the degree of the usability of the health information system. This implied that if a system was usable then the users would accept it; if it were not usable, then the users would reject it. The results of the research indicated otherwise. CHIME was a usable system; it was easy to use, efficient and effective. It facilitated the clinicians to manage all aspects of their clinical work, from basic record keeping, access, to collection and collation of statistics. However, the clinicians were not satisfied with it and did not accept it.

The clinician acceptance of any HIS needs to be evaluated along with the system's usability. The large costs involved in the implementation of HIS and the political implications of such costs in healthcare cannot allow for systems that are not accepted or used fully. More research needs to be done in this area.

\section{References}

1. NSW Health. NSW Health Strategy for the EHR NSW EHR* NET. (Report of the Health Information Management Implementation Coordination Group). NSW Health Department (2002)

2. Wickramasinghe, N., Sharma, S., Reddy, H.: Evidence-Based Medicine: A New Approach in the Practice of Medicine. In: Wickramasinghe, N., Gupta, J., Sharma, S. (eds.) Creating Knowledge-Based Healthcare Organizations, pp. 125-135. Idea Group Publishing, London (2005)

3. Safran, C., EMR: A Decade of Experience. Journal of the American Medical Informatics Association 285(13), 1766 (2001)

4. Spaziano, K.: EMR. Radiologic Technology 72(3), 287 (2001)

5. Gadd, C.: Dichotomy between Physicians and Patients Attitudes Regarding EMR Use During Outpatient Encounters. American Medical Information Association (2000)

6. Anderson, J.: Clearing the way for physicians use of clinical information systems. Communications of the ACM 40(8), 83-90 (1997)

7. Nielsen, A.C.: Attitudes towards IT in Australian General Practice (Qualitative Research Report, Computerisation in GP), vol. 2. Commonwealth Department of Health and Family Services, Canberra(1998)

8. DHAC. The Benefits and Difficulties of Introducing a National Approach to Electronic Health Records in Australia, Commonwealth Department of Health and Aged Care (2000)

9. Johnson, K.: Barriers that impede the adoption of pediatric IT. Archives of Pediatrics and Adolescent Medicine 155(12), 1374-1380 (2001)

10. Smith, A.: Human-Computer Factors: A Study of Users and Information Systems. McGraw-Hill, London (1997) 
11. Laerum, H., Ellingsen, G., Faxvaag, A.: Doctors use of electronic medical records systems in hospitals: cross sectional survey. British Medical Journal 323(7325), 1344-1349 (2001)

12. Kushniruk, A., Patel, V., Cimino, J.: Usability Testing in Medical Informatics: Cognitive Approaches to Evaluation of Information Systems and User Interfaces. In: Proceediings of 1997 AMIA Annual Fall Symposium, pp. 22-26 (1997)

13. ISO 9241-11 Ergonomic requirements for office work with visual display terminals (VDTs), Part 11: Guidance on Usability. ISO (1998)

14. Preece, J., Rogers, Y., Sharp, H., Benyon, D., Holland, S., Carey, T.: Human-Computer Interaction. Addison-Wesley, Harlow (1994)

15. Molich, R., Bevan, N., Butler, S., Curson, I., Kindlund, E., Kirakowski, J., Miller, D.: Comparative Evaluation of Usability Tests. In: Proceedings of the Usability Professionals Association Conference, pp. 189-200. UPA, Washington (1998)

16. Barnum, C.: Usability Testing and Research. Longman, New York (2002)

17. Davis, F.: Perceived Usefulness, Perceived Ease of Use and User Acceptance of IT. MIS Quarterly, 319-340 (1989)

18. Ajzen, I., Fishbein, M.: Understanding Attitudes and Predicting Social Behaviours. Prentice-Hall, Englewood Cliffs (1980)

19. Fishbein, M., Ajzen, I.: Belief, Attitude, Intention and Behaviour: An Introduction to Theory and Research. Addison-Wesley, Reading (1975)

20. Hubona, G., Geitz, S.: External Variables, Beliefs, Attitudes and IT Usage Behavior. In: Proceedings of the Thirtieth Annual Hawaii International Conference on System Sciences. IEEE, Los Alamitos (1997)

21. Dumas, J., Redish, J.: A Practical Guide to Usability Testing. Intellect Books, Exeter (1999) 